\title{
PEG tube placement in morbidly obese patients
}

We present two patients both of whom had severe morbid obesity and needed placement of a percutaneous endoscopic gastrostomy (PEG) for albumin and visceral protein replenishment. The first patient was a 53-year-old woman (body mass index [BMI], 85.8; weight, $191 \mathrm{~kg}$ ) who presented with respiratory distress and dysphagia; the second was a 26-year-old woman (BMI, 88.6; weight, $259 \mathrm{~kg}$ ) who presented with sepsis complicated by respiratory distress and dysphagia. Both women required placement of a PEG tube for long-term enteral nutrition.

In the first patient, transillumination was not possible due to the thickness of the overlying adipose tissue, so the site of needle insertion was selected by finger indentation/compression at the point where the abdominal wall appeared closest to the gastric wall. A 22-gauge, 8-inch long Tuohy spinal needle ( Fig. 1 ) was then inserted through the abdominal wall into the gastric lumen as a tracer needle ( $\bullet$ Fig. 2 ) With the application of external abdominal compression, the spinal needle was able to reach the stomach and cause "tenting" of the gastric mucosa and gastric lumen. A $240-\mathrm{cm}$ long guide wire (outer diameter $0.021 \mathrm{~cm}$; Boston Scientific Corp., Natick, Massachusetts, USA) usually used in endoscopic retrograde cholangiopancreatography (ERCP) was passed through the spinal needle into the gastric lumen, snared endoscopically, and pulled out through the mouth. The 22-gauge spinal needle was then replaced by an 18-gauge spinal needle and the $0.021-\mathrm{cm}$ guide wire was replaced by a $0.035-\mathrm{cm}$ guide wire, which was passed through the 18-gauge spinal needle. After this, standard methodology was used to slide the 20-gauge PEG tube over the wire and pull it out through the abdominal wall. The external bumper was located $8 \mathrm{~cm}$ from the internal bumper.

The technique for placement of the PEG tube was similar in the second patient except that a Boston kit wire (outer diameter $0.025 \mathrm{~cm}$; Boston Scientific Corp.) was guided through the 17-gauge spinal nee-

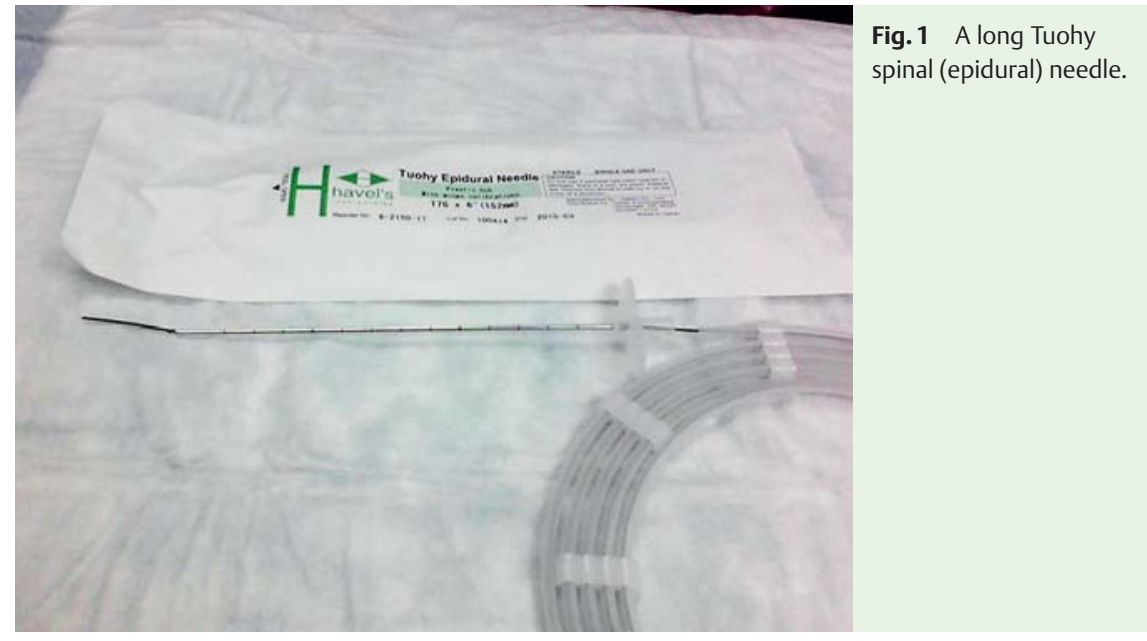

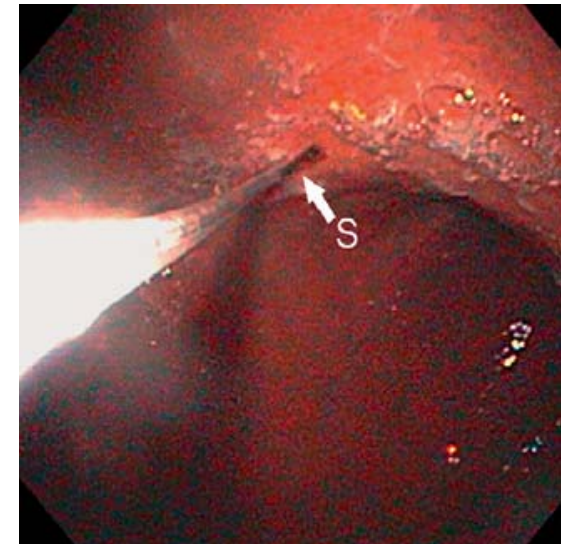

Fig. 2 Endoscopic view of the long 22-gauge spinal needle (S) within the gastric lumen having been passed through the full thickness of the overlying adipose tissue.

dle and the PEG tube was placed over this wire. The Boston wire has a slightly larger diameter, which fits the tapering end of the PEG tube firmly.

This new methodology utilizes the availability of long spinal needles and ERCP guide wires to overcome the difficulty of reaching the gastric lumen in severely morbidly obese patients with extremely thick abdominal walls.

\section{Endoscopy_UCTN_Code_TTT_1AO_2AK}

\section{Competing interests: None}

\section{Senadhi ${ }^{1}$, D. Emuron ${ }^{2}$, R. Singh ${ }^{2}$, S. Dutta ${ }^{3}$}

${ }^{1}$ Indiana University School of Medicine, Division of Gastroenterology and Hepatology; and Brater Scholar, Indiana Institute for Personalized Medicine, Indianapolis, Indiana, USA

2 Johns Hopkins University/Sinai Program, Department of Medicine, Baltimore, Maryland, USA

${ }^{3}$ University of Maryland School of Medicine, Division of Gastroenterology, Sinai Hospital, Baltimore, Maryland, USA

\section{Bibliography}

Dol http://dx.doi.org/ 10.1055/s-0031-1291527

Endoscopy 2012; 44: E53

(c) Georg Thieme Verlag KG Stuttgart · New York ISSN 0013-726X

\section{Corresponding author \\ Dr. Viplove Senadhi}

Division of Gastroenterology and Hepatology Indiana University

1050 Wishard Blvd, Suite 4100

Indianapolis, IN 46202

USA

Fax: +1-678-623-5999

vsenadhi@hotmail.com 